\title{
Foley's Catheter With or Without Misoprostol in Induction of Labor: Randomized Double Blind Control Study
}

\author{
Original \\ Article \\ Dina Mohamed Naguib Mahmoud, Khaled Mohamed Aziz Diab, Mai Medhat \\ Nawara
}

Department of Obstetrics and Gynecology, Faculty of Medicine, Ain-Shams University, Cairo

\begin{abstract}
Background: Labor induction is the initiation of labor at a viable pregnancy duration by artificial means, and occurs before the spontaneous onset of labor. The goal of labor induction is to achieve a timely and uncomplicated vaginal delivery with minimal adverse effects on the mother or newborn.

Aim: This study aimed to compare the efficacy of the use of Foley's catheter with either misoprostol or placebo to improve induction to delivery interval in women with unfavorable cervix undergoing induction of labor.

Materials and Methods: The present study is a randomized double blind controlled study that that was conducted at Maternity Hospital of Ain-Shams University. The study included 100 candidates on 4 equal goups :50 nulliparas randomized into 2 groups and 50 multiparas randomized into 2 groups. Each group underwent labor induction by Foley's catheter and Misoprostol or placebo.

Results: Labor stages were significantly shorter in combined group than in Foley's group, but no significant difference in third stage. Oxytocin duration and total dose were significantly lower in combined group. No significant difference among studied groups regarding mode of delivery or fetal or maternal complications.

Conclusion: Combined Foleys catheter and misoprostol provides a shorter duration of cervical ripening, less oxytocin required with no added complications compared to Foley's catheter alone.
\end{abstract}

Key Words: Foley's catheter, induction of labor, misoprostol

Received: 29 November 2019, Accepted: 27 July 2020

Corresponding Author: Dina Mohamed Naguib Mahmoud, Department of Obstetrics and Gynecology, Faculty of Medicine, Ain-Shams University, Cairo Tel.: 01007602893, E-mail: dnaguib22@gmail.com

ISSN: 2090-7265, February 2021, Vol.11, No. 1

\section{INTRODUCTION}

Recently, the rate of induction of labor has increased considerably. Approximately, $20 \%$ of all deliveries are initiated with this method ${ }^{[1]}$.

Labor induction is usually performed when benefits of delivery outweigh the risks of pregnancy continuation. Undoubtedly, cervical ripening has a fundamental relationship with the success rate of induction. Different methods are used for labor induction. Induction of labor with oxytocin in the presence of a low Bishop score is unlikely to lead to vaginal delivery in a suitable period of time and also is followed by high rate of cesarean section. Hence, methods of cervical ripening play an important role in modern obstetrics ${ }^{[2]}$.

Although there are many methods for cervical ripening, there exists no agreement on the best method for labor induction in cases with unripe cervix. Among these methods, cervical foley catheter and vaginal misoprostol (prostaglandin E1) are used for labor induction and cervical ripening ${ }^{[3]}$.
Since misoprostol is relatively cheap, stable at room temperature and has good effect, it is frequently used in obstetrics and gynaecology for termination of pregnancy especially at third trimester ${ }^{[4]}$.

Foley catheter balloon is currently the most commonly used mechanical device for labour induction. It acts by mechanical stretching of the cervix and stimulation of endogenous PG release from fetal membranes. The benefits of using it in induction are that it is safe, low cost, available, easily stored, lowest risk of uterine hyperstimulation and adverse FHR changes and possible alternative in case of home induction.

There is no clear evidence of an increased risk of chorioamniouitis. Levy et al. and Delaney et aL, reported that larger balloon volume was associated with shorter induction to delivery Interval without affecting cesarean section rate ${ }^{[5-7]}$.

\section{AIM OF THE WORK}

This study aims to compare the efficacy of the use 
of foley's catheter with either misoprostol or placebo to improve induction to delivery interval in pregnant women with unfavorable cervix undergoing induction of labor.

\section{PATIENTS AND METHODS}

The present study is a randomized double blind controlled study that was conducted at Maternity Hospital of Ain-Shams University (Department of Obstetrics and Gynaecology).

Sample size was calculated using PASS version 11 program, setting the type- 1 error $(\alpha)$ at 0.05 and the power $(1-\beta)$ at 0.9 . The results from a previous study ${ }^{[4]}$ showed that the mean duration to delivery among the combined group was $12.9 \pm 5.53$ while for foley's catheter only group it was $18.4 \pm 0.02^{[8]}$. Calculation according to these values produced a minimal sample size of 35 cases per group (70 total). As parity affects induction result, each arm had similar number of nullipara (25 case) and multipara ( 25 case) resulted in total of 50 patients in each group ${ }^{[8]}$.

Women were enrolled by the doctors in the labor room. They were randomly allocated to induction with foley's balloon catheter and oral misoprostol or foley's catheter with placebo.

Allocation and concealment: One hundred envelopes were numbered serially and in each envelope the corresponding letter which denotes the allocated group was put according to randomization table. Two boxes were made; one for nullipara patients (envelopes from 1 to 52) and other for multipara patients (envelopes from 52 to 104). Women were counseled about the procedure in detail before initiating the research and as hospital practice, consent for emergency CS was taken in case of induction failure or emergency occurrence.

Inclusion criteria: singleton gestation, cephalic presentation, at term (gestational age $\geq 37$ weeks) with intact membranes and Bishop score $\leq 4$ with an indication for labor induction ${ }^{[9]}$.

Exclusion criteria: cases with rupture of membranes, chorioamnionitis, antepartum haemorrhage, cervical dilation $>3 \mathrm{~cm}$ (or Bishop score $>4$ ), contracted pelvis, history of placenta previa or unexplained vaginal bleeding, history of previous CS or other uterine surgery, any contraindication to use of prostaglandins (e.g. hypersensitivity, asthma), acute pelvic inflammatory disease, or any contraindication to vaginal delivery. Women with a non-reassuring fetal heart rate pattern prior to induction were also excluded.

In this study, the oral misoprostol dose was $(25-\mu \mathrm{g})$ repeated every $2 \mathrm{~h}$. The $200 \mathrm{mg}$ cytotec (misoprostol) tab was dissolved in $80 \mathrm{ml}$ water and divided into 8 doses. A similar $80 \mathrm{ml}$ placebo solution was prepared for control arm. Each woman in any of the two groups took $10 \mathrm{ml}$ solute per dose (either with drug dissolved or placebo $)^{[10]}$.

The doses were withheld if regular contractions were established (three contractions per $10 \mathrm{~min}$ ), or if tachysystole ( $>5$ contractions in $10 \mathrm{~min}$ ), hypersystole ( single contraction lasting $\geq 2 \mathrm{~min}$ ) or hyperstimulation (tachysystole or hypersystole with non-reassuring fetal heart rate).

Foley's catheter (a 16 or 18 Fr Foley's catheter) was introduced into the cervix under direct visualization with a sterile speculum. The balloon was filled with 50 $\mathrm{cm} 3$ of $0.9 \% \mathrm{NaCl}$ or water. The Foley's catheter was fixed to maintain traction. The catheter was checked for extrusion of the balloon from the cervix every 4 hours by cervical examination until the balloon was expelled spontaneously.

Labor augmentation followed as indicated by hospital protocol by either artificial membrane rupture or oxytocin drip according to hospital protocol.

The primary outcome measure was induction to delivery interval. While, the secondary outcome measures included uterine contractile abnormalities, mode of delivery, maternal and neonatal outcome, neonatal birth weight and Apgar score. The amount of oxytocin used for induction was calculated.

\section{STATISTICAL ANALYSIS:}

The collected data were coded, tabulated, and statistically analyzed using IBM SPSS statistics (Statistical Package for Social Sciences) software version 18.0, IBM Corp., Chicago, USA, 2009.

Descriptive statistics were done for quantitative data as minimum and maximum of the range as well as mean $\pm \mathrm{SD}$ (standard deviation) for quantitative normally distributed data, median and 1 st\& 3 rd inter-quartile range for quantitative non-normally distributed data, while it was done for qualitative data as number and percentage.

Inferential analyses were done for quantitative variables using $\mathrm{K}-\mathrm{S}$ test for normality testing, independent t-test in cases of two independent groups with normally distributed data and Mann Whitney U in cases of two independent groups with non-normally distributed data. In qualitative data, inferential analyses for independent variables were done using Fisher's Exact test for variables with small expected numbers. 
Long rank test was used to compare rates. The level of significance was taken at $P$ value $<0.050$ is significant, otherwise is non-significant.

\section{RESULTS}

Table 1 showed that oxytocin duration and total dose were significantly lower in combined group than in Foley's group in both nullipara and multipara.

Table 2 showed that no significant difference between the studied nullipara and multipara groups regarding mode of delivery and indications of CS.

Table 3 showed that labor stages were significantly shorter in combined group than in Foley's group.

Table 4 showed that combined group non-significantly had more frequent uterine hyperstimulation and perineal tear but less frequent postpartum hemorrhage.

Table 5 showed that no significant difference between the studied nullipara and multipara groups regarding fetal and neonatal side effects.

Table 1: Comparison between studied groups regarding oxytocin administration

\begin{tabular}{|c|c|c|c|c|}
\hline NULLIPARA & Measures & $\begin{array}{c}\text { Combined } \\
(\mathrm{N}=25)\end{array}$ & $\begin{array}{l}\text { Foley's } \\
(\mathrm{N}=25)\end{array}$ & $\wedge P$ \\
\hline \multirow{3}{*}{ Duration (hours) } & Mean \pm SD & $6.6 \pm 1.6$ & $8.8 \pm 1.6$ & \multirow{3}{*}{$<0.001 *$} \\
\hline & & & & \\
\hline & Range & $3.4-8.2$ & $5.1-11.1$ & \\
\hline \multirow{3}{*}{$\begin{array}{l}\text { Total dose } \\
\text { (IU) }\end{array}$} & Mean \pm SD & $9.8 \pm 4.1$ & $12.7 .0 \pm 4.9$ & \multirow{3}{*}{$0.033^{*}$} \\
\hline & & & & \\
\hline & Range & $3.0-16.0$ & $5.0-20.0$ & \\
\hline \multirow[t]{2}{*}{ MULTIPARA } & Measures & $\begin{array}{c}\text { Combined } \\
(\mathrm{N}=25)\end{array}$ & $\begin{array}{l}\text { Foley's } \\
(\mathrm{N}=25)\end{array}$ & $\wedge P$ \\
\hline & Mean \pm SD & $4.8 \pm 1.8$ & $6.5 \pm 2.1$ & \multirow{3}{*}{$0.005 *$} \\
\hline \multirow[t]{2}{*}{ Duration (hours) } & & & & \\
\hline & Range & $1.4-8.0$ & $3.2-10.9$ & \\
\hline \multirow{3}{*}{$\begin{array}{l}\text { Dose } \\
\text { (IU) }\end{array}$} & Mean \pm SD & $6.1 \pm 2.9$ & $8.0 \pm 3.4$ & \multirow{3}{*}{$0.037^{*}$} \\
\hline & & & & \\
\hline & Range & $1.0-12.0$ & $3.0-15.0$ & \\
\hline
\end{tabular}

${ }^{\wedge}$ Independent t-test *Significant, CI: Confidence interval 
Table 2: Mode of delivery and indications of CS among the studied groups

\begin{tabular}{|c|c|c|c|c|c|}
\hline NULLIPARA & Findings & $\begin{array}{l}\text { Combined } \\
(\mathrm{N}=25)\end{array}$ & $\begin{array}{l}\text { Foley's } \\
(\mathrm{N}=25)\end{array}$ & $P$ & $\begin{array}{c}\mathrm{RR} \\
(95 \% \mathrm{CI})\end{array}$ \\
\hline \multirow[t]{3}{*}{$\begin{array}{l}\text { Mode of } \\
\text { delivery }\end{array}$} & $\mathrm{CS}$ & $6(24.0 \%)$ & $4(16.0 \%)$ & \# 0.480 & $\begin{array}{c}1.50 \\
(0.48-4.68)\end{array}$ \\
\hline & VD & $19(76.0 \%)$ & $21(86.0 \%)$ & & \\
\hline & Fetal distress & 3 & 1 & & \\
\hline \multirow[t]{2}{*}{ of CS } & Non progressive & 2 & 2 & $\& 1.000$ & -- \\
\hline & Obstructed & 1 & 1 & & \\
\hline MULTIPARA & Findings & $\begin{array}{l}\text { Combined } \\
(\mathrm{N}=25)\end{array}$ & $\begin{array}{l}\text { Foley's } \\
(\mathrm{N}=25)\end{array}$ & $P$ & $\begin{array}{c}\mathrm{RR} \\
(95 \% \mathrm{CI})\end{array}$ \\
\hline \multirow[t]{2}{*}{$\begin{array}{l}\text { Mode of } \\
\text { delivery }\end{array}$} & CS & $3(12.0 \%)$ & $2(8.0 \%)$ & \# 0.480 & $\begin{array}{c}1.50 \\
(0.27-8.22)\end{array}$ \\
\hline & VD & $22(88.0 \%)$ & $23(92.0 \%)$ & & \\
\hline \multirow[t]{2}{*}{$\begin{array}{l}\text { Indications } \\
\text { of } \mathrm{CS}\end{array}$} & Fetal distress & 2 & 1 & $\& 1.000$ & $\begin{array}{c}2.00 \\
(0.19-20.67)\end{array}$ \\
\hline & Non progressive & 1 & 1 & & \\
\hline
\end{tabular}

^Independent t-test. \#Chi square test \& Fisher's Exact test 
Table 3: Comparison between nullipara and multipara groups regarding labor stages

\begin{tabular}{|c|c|c|c|c|}
\hline \multirow[b]{2}{*}{ Stage } & \multicolumn{3}{|c|}{ Nullipara } & \multirow[b]{2}{*}{$\wedge P$} \\
\hline & Measures & $\begin{array}{l}\text { Combined } \\
(\mathrm{N}=19)\end{array}$ & $\begin{array}{l}\text { Foley's } \\
(\mathrm{N}=21)\end{array}$ & \\
\hline \multirow[t]{2}{*}{$\begin{array}{l}\text { Latent } \\
\text { (hours) }\end{array}$} & Mean \pm SD & $5.8 \pm 0.5$ & $6.8 \pm 0.6$ & \multirow[t]{2}{*}{$<0.001^{*}$} \\
\hline & Range & $3.8-6.4$ & $5.2-7.6$ & \\
\hline \multirow[t]{2}{*}{$\begin{array}{l}\text { Active } \\
\text { (hours) }\end{array}$} & Mean \pm SD & $6.5 \pm 0.3$ & $7.4 \pm 0.6$ & \multirow[t]{2}{*}{$<0.001^{*}$} \\
\hline & Range & $5.5-6.8$ & $6.6-8.5$ & \\
\hline \multirow{2}{*}{$\begin{array}{l}\text { Second } \\
\text { (minutes) }\end{array}$} & Mean \pm SD & $26.9 \pm 1.6$ & $30.8 \pm 3.0$ & \multirow[b]{2}{*}{$<0.001^{*}$} \\
\hline & Range & $21.0-29.0$ & $27.0-36.0$ & \\
\hline \multirow[t]{2}{*}{$\begin{array}{l}\text { Third } \\
\text { (minutes) }\end{array}$} & Mean \pm SD & $6.3 \pm 1.9$ & $7.2 \pm 1.6$ & \multirow[t]{2}{*}{0.098} \\
\hline & Range & $3.0-9.0$ & $4.0-10.0$ & \\
\hline \multirow[t]{2}{*}{$\begin{array}{l}\text { Total } \\
\text { (hours) }\end{array}$} & Mean \pm SD & $12.9 \pm 0.9$ & $14.8 \pm 1.1$ & \multirow[t]{3}{*}{$<0.001^{*}$} \\
\hline & Range & $9.7-13.8$ & & \\
\hline \multirow{3}{*}{$\begin{array}{l}\text { Latent } \\
\text { (hours) }\end{array}$} & & Multipara & & \\
\hline & Mean \pm SD & $4.1 \pm 0.9$ & $4.8 \pm 1.0$ & \multirow[t]{2}{*}{$0.031 *$} \\
\hline & Range & $2.8-5.7$ & $3.1-6.9$ & \\
\hline \multirow{2}{*}{$\begin{array}{l}\text { Active } \\
\text { (hours) }\end{array}$} & Mean \pm SD & $5.4 \pm 0.6$ & $6.1 \pm 1.0$ & \multirow{2}{*}{$0.012 *$} \\
\hline & Range & $4.3-6.2$ & $4.5-8.4$ & \\
\hline \multirow{2}{*}{$\begin{array}{l}\text { Second } \\
\text { (minutes) }\end{array}$} & Mean \pm SD & $22.0 \pm 3.8$ & $24.9 \pm 4.0$ & \multirow{2}{*}{$0.016^{*}$} \\
\hline & Range & $12.0-28.0$ & $18.0-36.0$ & \\
\hline \multirow[t]{2}{*}{$\begin{array}{l}\text { Third } \\
\text { (minutes) }\end{array}$} & Mean \pm SD & $5.5 \pm 1.4$ & $6.4 \pm 1.8$ & \multirow[t]{2}{*}{0.073} \\
\hline & Range & $3.0-8.0$ & $3.0-10.0$ & \\
\hline \multirow[t]{2}{*}{$\begin{array}{l}\text { Total } \\
\text { (hours) }\end{array}$} & Mean \pm SD & $10.1 \pm 1.5$ & $11.3 \pm 2.1$ & \multirow[t]{2}{*}{$0.018^{*}$} \\
\hline & Range & $7.7-12.5$ & $8.0-15.9$ & \\
\hline
\end{tabular}

${ }^{\wedge}$ Independent t-test *Significant, CI: Confidence interval 
Table 4: Maternal side effects among the studied nullipara and multipara groups

\begin{tabular}{|c|c|c|c|c|}
\hline \multicolumn{5}{|c|}{ NULLIPARA } \\
\hline Side effects & $\begin{array}{c}\text { Combined } \\
(\mathrm{N}=25)\end{array}$ & $\begin{array}{l}\text { Foley's } \\
(\mathrm{N}=25)\end{array}$ & $\# \mathrm{P}$ & $\begin{array}{c}\mathrm{RR} \\
(95 \% \mathrm{CI}\end{array}$ \\
\hline Uterine hyperstimulation & $5(20.0 \%)$ & $1(4.0 \%)$ & 0.189 & $5.00(0.63-39.79)$ \\
\hline Perineal tear & $9(36.0 \%)$ & $4(16.0 \%)$ & 0.196 & $2.25(0.80-6.36)$ \\
\hline Post partum hemorrhage & $1(4.0 \%)$ & $2(8.0 \%)$ & 1.000 & $0.50(0.05-5.17)$ \\
\hline \multicolumn{5}{|c|}{ MULTIPARA } \\
\hline Uterine hyperstimulation & $3(12.0 \%)$ & $1(4.0 \%)$ & 0.609 & $3.00(0.33-26.92)$ \\
\hline Perineal tear & $4(16.0 \%)$ & $2(8.0 \%)$ & 0.667 & $2.00(0.40-9.95)$ \\
\hline Post partum hemorrhage & $2(8.0 \%)$ & $4(16.0 \%)$ & 0.667 & $0.50(0.10-2.49)$ \\
\hline
\end{tabular}

\#Fisher's Exact test 
Table 5: Fetal and neonatal side effects among the studied nullipara and multipara groups

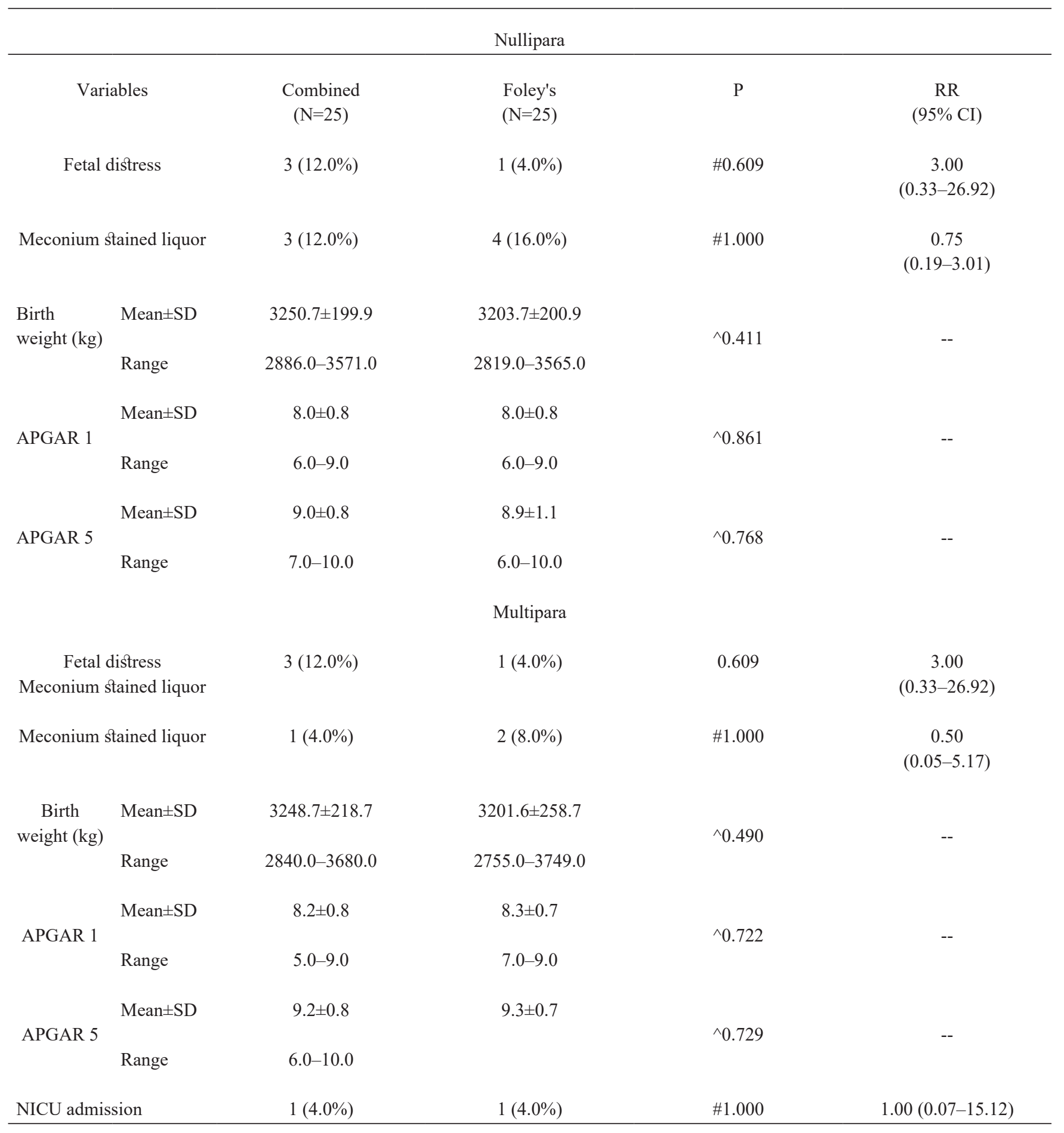

$\wedge$ Independent t-test. \#Fisher's Exact test 


\section{DISCUSSION}

This randomized double blind controlled study aimed to compare the efficacy of the use of Foley's catheter with either misoprostol or placebo to improve induction to delivery interval in pregnant women with unfavorable cervix undergoing induction of labor on similar number of nullipara ( 25 case) and multipara ( 25 case) to be of total 50 patients in each group. It was performed in Maternity Hospital of Ain-Shams University.

The primary outcome was induction to delivery interval, while secondary outcomes were uterine contractile abnormalities, mode of delivery, maternal and neonatal outcome, neonatal birth weight, Apgar score, any maternal or fetal complication and the amount of oxytocin used for induction

In this study, no significant difference between the studied groups regarding demographic characteristics as age, BMI, GA and Bishop Score $(p=0.238,0.839,0.490$ and 0.460 , respectively).

In current study, oxytocin duration and total dose were significantly lower in combined group $(6.6 \pm 1.6$ and $9.8 \pm 4.1$, respectively) than in Foley's group $(8.8 \pm 1.6$ and $12.7 .0 \pm 4.9$, respectively) as $p<0.001$ and 0.033 , respectively. It is therefore not surprising that oxytocin requirement in labor was significantly lower in the combined group than in the other two groups in this study. This is because the use of either Foley's catheter or misoprostol alone is capable of stimulating endogenous release of oxytocin. Therefore, combining these two agents will ultimately result in less oxytocin requirement in labor than using either agent alone.

This was similarly reported by Barrilleaux et al. who used combined Foley's catheter and dinoprostone gel $^{[11]}$. Also, similarly, Aduloju et al., conducted their study to compare the efficacy of combined Foley's catheter and vaginal misoprostol with Foley's catheter or low-dose vaginal misoprostol alone for cervical ripening on the three groups; group A (Foley's catheter group), group B (low-dose misoprostol group) and group C (combination of Foley's catheter and low-dose misoprostol). The requirement for oxytocin in labor among the three groups was significantly different: $31.4 \%$ group C, $61.4 \%$ group B and $94.3 \%$ group $\mathrm{A}, P=0.001$. Women in group $\mathrm{C}$ required significantly lower doses of oxytocin in labor than women in group B $(P=0.001)$ and group A $(P<0.001)$, respectively ${ }^{[2]}$.

In contrary, the requirement of oxytocin administration was similar between the two groups in the study conducted by Hill et al. in 2009. Only six patients in the oral misoprostol and Foley (group II) received the maximum dose, and none of the patients in group I (vaginal misoprostol) received the maximum $\operatorname{dose}^{[4]}$.

Also, Chung et al., found the labor management was comparable among the three groups (Misoprostol group, Foley catheter group and combination group). There was no difference in the use of oxytocin during labor $^{[12]}$.

In the current study, there was non-significant difference between the studied regarding mode of delivery and indications of CS ( $p=0.480$ and 1.000, respectively). Although, the majority of both group had VD (76.0\% and $86.0 \%$, respectively) and half of cases in combined group, the CS was indicated due to Fetal distress and in foley group due to nonprogressive labor.

Aduloju et al., found no significant difference in the route of delivery even though women in combination group C (78.6\%) achieved more vaginal deliveries than women in misoprostol group B $(72.9 \%)$ and foley catheter group A (68.6\%), $P=0.406$. Out of those that had vaginal delivery, $92.7 \%, 88.2 \%$ and $68.7 \%$ of the groups $\mathrm{C}, \mathrm{B}$ and $\mathrm{A}$, respectively, delivered within $12 \mathrm{~h}$. The indications for caesarean section were similar among the three groups $(P=0.878)^{[2]}$.

According to Hill et al., the overall rate of cesarean delivery was equivalent between the two subgroups. The incidence of intervention by cesarean delivery for non-reassuring fetal heart rate status did not differ significantly between the two groups $(49 \% \text { versus } 63 \%, p=0.20)^{[4]}$.

Also, according to Chung et al., there was no statistically significant difference in vaginal delivery rates $(63.3 \%$ in the misoprostol group, $57.4 \%$ in the Foley group and $58.1 \%$ in the combination group; $P=.81$ ). A subanalysis of nulliparous patients showed no statistically significant difference in the rate of vaginal delivery; $16 / 33(48 \%)$ in the misoprostol group, $16 / 33(48 \%)$ in the Foley group and $14 / 31(45 \%)$ in the combination group $(P=.95)$. There was also no statistically significant difference in the rate of vaginal delivery among multiparous patients; $15 / 16(94 \%)$ in the misoprostol group, $15 / 21 \quad(71 \%)$ in the Foley group and $11 / 12(92 \%)$ in the combination group $(P=.13)^{[12]}$.

Lanka et al., stated the same results when comparing combining foley's catheter with misoprostol versus misoprostol alone for induction. The rate of CS was the same in both groups. Lanka et al. ${ }^{[13]}$ and same results obtained by Carbone et al. ${ }^{[14]}$. 
Comparison between nullipara groups

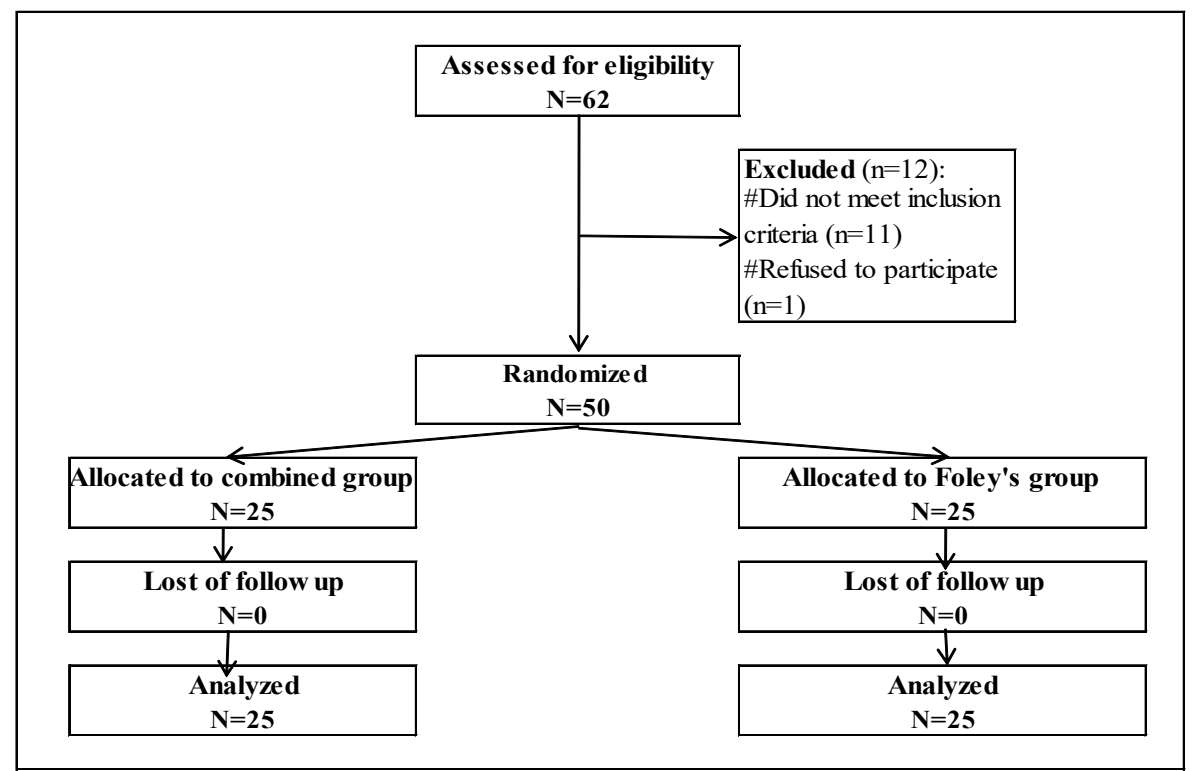

Fig. 1: Flow chart of the studied nullipara cases

Comparison between multipara groups

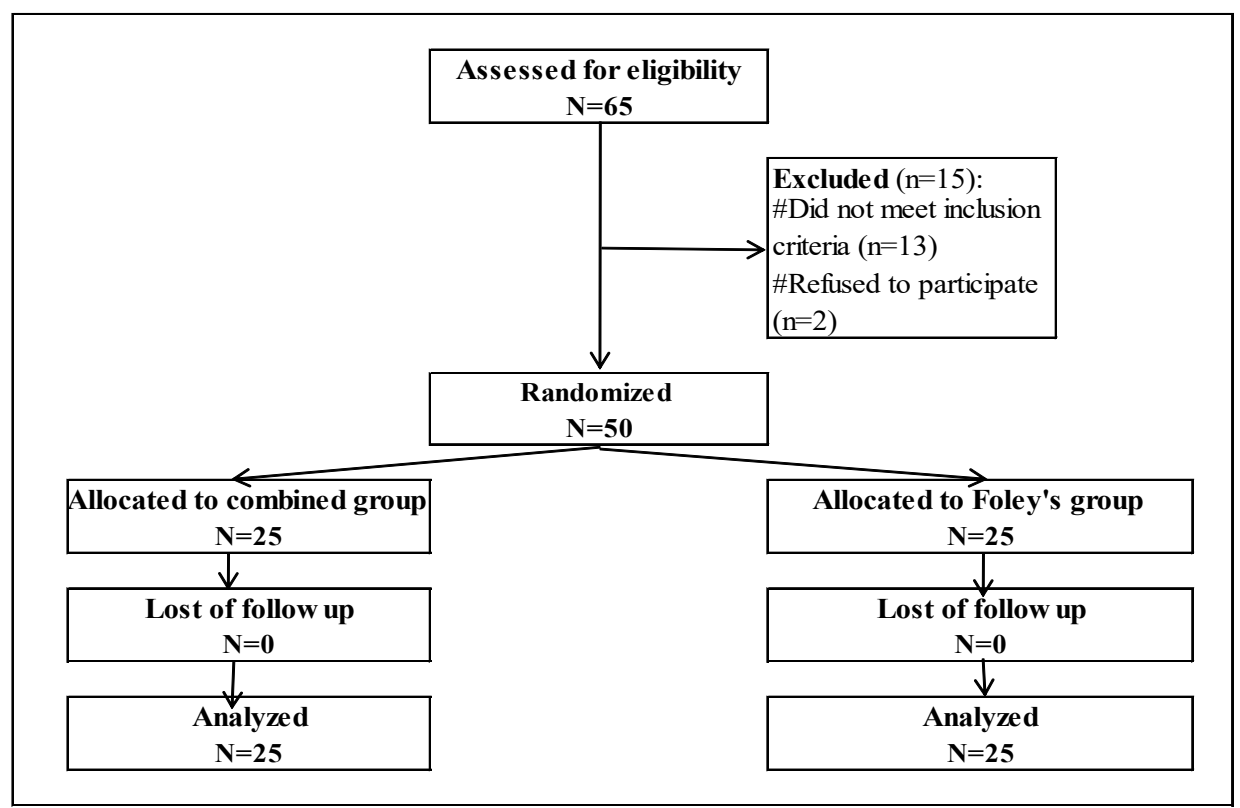

Fig. 2 : Flow chart of the studied multipara cases 
On the contrary, Moraes Filho et al., who compared misoprostol to foley's catheter for induction stated that rate of vaginal delivery is significantly higher in the misoprostol group as well as decreased induction interval ${ }^{[15]}$.

In this study, the labor stages (latent, active, second and total) were significantly shorter in the combined group $(5.8 \pm 0.5,6.5 \pm 0.3,26.9 \pm 1.6$ and $12.9 \pm 0.9$ respectively) than in the Foley's group $(6.8 \pm 0.6,7.4 \pm$ $0.6,30.8 \pm 3.0$ and $14.8 \pm 1.1)(p<0.001$ for all $)$. On the other hands, no significant difference in the third stage $(6.3 \pm 1.9$ versus $7.2 \pm 1.6$ and $p=0.098)$.

Hill et al. in 2008 reported that the duration between induction and delivery in Foley catheter plus oral misoprostol group was significantly shorter than that of vaginal misoprostol group ${ }^{[4]}$.

Fekrat et al. studied three methods of cervical ripening and labor induction with vaginal misoprostol and Foley catheter and a combination of these two methods. The duration between induction of labor and delivery was significantly lower in misoprostol group, but they concluded that the combination of these two methods didn't have more efficacy on cervical ripening ${ }^{[16]}$.

Of the patients who achieved successful vaginal delivery, there was no statistically significant difference in the interval between induction to delivery. However, a shorter induction to active phase interval was noted in the patients who received combination therapy compared with those who received misoprostol or Foley catheter alone in a similar study ${ }^{[12]}$.

In some previous studies, the mean time to delivery was significantly shorter in misoprostol group rather than the Foley catheter group ${ }^{[15,17,18,19]}$.

Lanka et al., stated that adding Foley's catheter to misoprostol did not cause any statistically difference in reducing induction to delivery time ${ }^{[13]}$.

In this study, combined group non-significantly had more frequent uterine hyperstimulation $(20.0 \%$ versus $4.0 \%)$ and perineal tear $(36.0 \%$ versus $16.0 \%)$ but less frequent postpartum hemorrhage $(4.0 \%$ versus $8.0 \%$ ) as $p=0.189,0.196$ and 1.000 , respectively.

There were no reported cases of uterine contractile abnormalities such as hyperstimulation, hypertonus and tachysystole in the study by Aduloju et al. ${ }^{[2]}$ and this was similarly reported by Ugwu et al. ${ }^{[20]}$. This may be due to the fact that the same dosage of $25 \mathrm{ug}$ of misoprostol was used in both studies; but previous studies have reported rates of uterine contractile abnormalities of $0-36.7 \%$ based on different doses and dosing intervals of intravaginal misoprostol ${ }^{[15,18]}$.

According to finding by Vahid Roudsari et al., tachysystole was observed in $2 \%$ of the misoprostol group patients and no one of the Foley catheter group $(p>0.1) .5 \%$ of the first group and $6 \%$ of the second group were complicated by atony after delivery $(p>0.1)$. The uterine hypertonus defined as contractions lasted more than two min was observed in $2 \%$ of the first group and no one of second group ${ }^{[19]}$.

However, Chung et al., found the tachysystole, hyperstimulation and the use of terbutaline occurred more frequently in the misoprostol group compared with the Foley group and the combination group ${ }^{[12]}$.

Both Al- Ibraheemi et al., and Lanka et al. ${ }^{[13]}$ found that adding Foley's catheter to misoprostol reduces the rate of uterine hyperstimulation compared to using misoprostol alone ${ }^{[21]}$.

In current study, no significant difference between the studied groups regarding fetal and neonatal side effects as fetal distress, meconium stained liquor, birth weight, APGAR1, APGAR5 and NICU admission as $p=0.609,1.000,0.411,0.861,0.768$ and 1.000 , respectively. Some other studies reported the same results ${ }^{[4,16]}$.

As reported by Vahid Roudsari et al., who studied the two groups; misoprostol group as first group and Foley catheter group as second group. In the first group, the mean of neonatal birthweight was $3182 \pm 430 \mathrm{~g}$, first min Apgar was 8, five min Apgar was 9, and the rate of meconial amniotic fluid expulsion was $10 \%$. In second group, the mean of neonatal birthweight was $3323.8 \pm 353 \mathrm{~g}$, first min Apgar was 8, five min Apgar was 9, and the rate of meconial amniotic fluid expulsion was $5 \%{ }^{[19]}$.

The neonatal outcomes, including birth weight, meconium-stained liquor, Apgar score, admission into the NICU are similar in several studies ${ }^{[2,4,12,20]}$.

Chung et al. found an increased rate of chorioamnionitis in the combination group, but this did not reach statistical significance. There was no difference in the rate of meconium-stained amniotic fluid or endometritis ${ }^{[12]}$.

\section{CONCLUSION}

Combined Foley's catheter and misoprostol provides a shorter duration of cervical ripening, less 
oxytocin required but more $\mathrm{CS}$ indicated and fetal distress (yet non-statistically significant) compared to Foley's catheter alone.

\section{CONFLICT OF INTEREST}

There are no conflicts of interests.

\section{REFERENCES}

1. Chen W, Xue J, Gaudet L, et al. (2015): Metaanalysis of Foley catheter plus misoprostol versus misoprostol alone for cervical ripening. International Journal of Gynecology \& Obstetrics 129: 193-198.

2. Aduloju OP, Akintayo AA, Adanikin AI, et al. (2016): Combined Foley's catheter with vaginal misoprostol for pre-induction cervical ripening: A randomised controlled trial. Australian and New Zealand Journal of Obstetrics and Gynaecology 56: $578-584$

3. Eikelder MLG, Mast K, van der Velden A, et al. (2016): Induction of Labor Using a Foley Catheter or Misoprostol: A Systematic Review and Metaanalysis. Obstetrical \& gynecological survey 71: 620-630.

4. Hill JB, Thigpen BD, Bofill JA, et al. (2009): A randomized clinical trial comparing vaginal misoprostol versus cervical Foley plus oral misoprostol for cervical ripening and labor induction. American journal of perinatology 26: 033-038.

5. Delaney S, Shaffer BL, Cheng YW, et al. (2010) Labor Induction With a Foley Balloon Inflated to $30 \mathrm{~mL}$ Compared With $60 \mathrm{~mL}$ : A Randomized Controlled Trial. Obstetrics \& Gynecology 115: 1239-1245.

6. Levy R, Kanengiser B, Furman B, et al. (2004): A randomized trial comparing a $30-\mathrm{mL}$ and an $80-\mathrm{mL}$ Foley catheter balloon for preinduction cervical ripening. American journal of obstetrics and gynecology 191: 1632-1636.

7. Gu N, Ru T, Wang Z, et al. (2015) Foley Catheter for Induction of Labor at Term: An Open-Label,
Randomized Controlled Trial. PLoS ONE 10: e0136856.

8. Kashanian M, Fekrat $\mathrm{M}$, Naghghash $\mathrm{S}$, et al. (2008): Evaluation of the effect of extra-amniotic normal saline infusion alone or in combination with dexamethasone for the induction of labor. Journal of Obstetrics and Gynaecology Research 34: 47-50.

9. Noor N, Ansari M, Ali M (2013): Comparison of vaginal misoprostol and Foley catheter for cervical Ripening. IJSR 2013:6.14

10. Bishop EH (1964): Pelvis scoring for elective induction. ObstetGynecol; 24:266-8.

11. WHO (2011): recommendations for induction of labor.

12. Barrilleaux PS, Bofill JA, Terrone DA, et al. (2002): Cervical ripening and induction of labor with misoprostol, dinoprostone gel, and a Foley catheter: a randomized trial of 3 techniques. American journal of obstetrics and gynecology 186: 1124-1129.

13. Chung JH, Huang WH, Rumney PJ, et al. (2003): A prospective randomized controlled trial that compared misoprostol, Foley catheter, and combination misoprostol-Foley catheter for labor induction. American journal of obstetrics and gynecology 189: 1031-1035.

14. Lanka S, Surapanine T, et al. (2014): Concurrent use of foley catheter and misoprostol for induction of labor. journal of obstetrics and gynecology research 40: 1527- 1533 .

15. Carbone JF, Tuuli MG, Fogertey PJ et al. (2013): Combination of foley bulb and vaginal misoprostol compared with vaginal misoprostol alone for cervical ripening and labor induction. American journal of obstetrics and gynecology 121

16. Filho OBM, Albuquerque RM and Cecatti JG (2010): A randomized controlled trial comparing vaginal misoprostol versus Foley catheter plus 
oxytocin for labor induction. Acta obstetricia et gynecologica Scandinavica 89: 1045-1052.

17. Fekrat M, Kashanian M, Alavi M, et al. (2007): Comparison of 3 techniques for cervical ripening and induction of labor with vaginal misoprostol and foley catheter and combination of these two methods. Journal of Fertility and Infertility 8: 149-154.

18. Dalui R, Suri V, Ray P, et al. (2005): Comparison of extraamniotic Foley catheter and intracervical prostaglandin E 2 gel for preinduction cervical ripening. Acta obstetricia et gynecologica Scandinavica 84: 362-367.

19. Adeniji A, Olayemi O and Odukogbe A (2006): Intravaginal misoprostol versus transcervical
Foley catheter in pre-induction cervical ripening. International Journal of Gynecology and Obstetrics 92: 130-132.

20. Vahid Roudsari F, Ayati S, Ghasemi M, et al. (2011): Comparison of vaginal misoprostol with foley catheter for cervical ripening and induction of labor. Iran J Pharm Res 10: 149-154.

21. Ugwu E, Onah H, Obi S, et al. (2013): Effect of the Foley catheter and synchronous low dose misoprostol administration on cervical ripening: a randomised controlled trial. Journal of Obstetrics and Gynaecology 33: 572-577.

22. Al-Ibraheemi Z, Brustman L, Bimson $\mathrm{E}$ et al. (2018): Misoprostol with foley bulb compared with misoprostol alone for cervical ripening. American journal of obstetrics and gynecology 121 